\title{
Increased musashi 2 expression indicates a poor prognosis and promotes malignant phenotypes in gastric cancer
}

\author{
ZIGUO YANG ${ }^{*}$, JIE LI $^{*}$, YULONG SHI, LEPING LI and XIAOBO GUO \\ Department of Gastrointestinal Surgery, Shandong Provincial Hospital Affiliated to Shandong University, \\ Jinan, Shandong 250021, P.R. China
}

Received February 25, 2017; Accepted June 6, 2018

DOI: $10.3892 /$ ol.2019.9889

\begin{abstract}
Musashi 2 (MSI2), a marker of stem and progenitor cells, has been identified as an oncogene. Various investigations have revealed that MSI2 is differently expressed in several types of blood cancer and solid cancers. However, its expression and biological functions in gastric cancer (GC) remain unclear. In the present study, MSI2 mRNA and protein expression were assessed in GC tissue samples. The associations between MSI2 mRNA expression and the clinicopathological characteristics of patients with GC were analyzed, and the effect of MSI2 on the prognosis of patients with GC was verified. The biological functions of MSI2 in GC cells were assessed using gain-of-function assays in vitro. The results revealed that MSI2 was overexpressed in the majority of GC tissue samples, although this difference was not significant. MSI2 mRNA expression levels were associated with invasion depth, tumor-node-metastasis stage, degree of differentiation and tumor size $(\mathrm{P}<0.05)$, but were not associated with sex, age, tumor location or human epidermal growth factor receptor 2 expression. Increased MSI2 expression resulted in a poorer prognosis in patients with $\mathrm{GC}\left(\chi^{2}=4.221 ; \mathrm{P}=0.040\right)$. In vitro assays revealed that MSI2 promoted MKN-28 cell proliferation, migration and invasion, and promoted tube formation in HUVECs. Although no significance of MSI2 expression was found, its oncogenic functions in the GC cell line indicated that MSI2 may be a potential oncogene that may serve as a biomarker for GC diagnosis and prognosis with verification from a larger sample and more GC cell lines.
\end{abstract}

Correspondence to: Professor Xiaobo Guo, Department of Gastrointestinal Surgery, Shandong Provincial Hospital Affiliated to Shandong University, 324 Jingwu Road, Jinan, Shandong 250021, P.R. China

E-mail: guo992352@hotmail.com

${ }^{*}$ Contributed equally

Key words: musashi 2, gastric cancer, prognosis, proliferation, migration, invasion, angiogenesis

\section{Introduction}

Gastric cancer (GC) is one of the most common malignancies globally (1). Despite a general decline in morbidity, GC is still one of the leading causes of cancer-associated mortality in males from less well-developed countries $(2,3)$. Surgery is the primary form of treatment for this disease, and adjuvant chemotherapy has made significant progress in recent years (4). However, the prognosis of patients with GC who are diagnosed at advanced stage remains poor (5). Therefore, it is necessary to develop more effective therapeutic strategies in order to decrease the mortality rate of GC. Tumorigenesis and progression of GC are known to be multistep processes involving the alteration of oncogenes and tumor suppressor genes $(6,7)$. GC-associated genes that regulate the malignant phenotype are potential therapeutic targets for GC treatment (8); therefore, it is necessary to screen for genes that are specific and sensitive.

The RNA-binding protein musashi (MSI) family are markers of stem cells and progenitor cells, which inhibit the translation of certain mRNAs and maintain the stem-cell state, also affecting cell differentiation and tumorigenesis $(9,10)$. The family contains two paralogues, MSI1 and MSI2. These genes are also expressed in cancer cells and are associated with cell differentiation and the regulation of epithelial-to-mesenchymal transition (EMT) via inhibition of Jagged1 (11). MSI2 is predominantly expressed in hematopoietic stem cells (HSCs), where it modulates engraftment and the depletion of HSCs, and is overexpressed in myeloid leukemia, where it regulates cell proliferation ad apoptosis and indicates a poor prognosis (12). MSI2 has also been demonstrated to be involved in certain solid carcinomas. For example, MSI2 is upregulated in hepatocellular carcinoma (HCC) (13) and colorectal adenocarcinomas (14), and its upregulation promotes cell growth and invasion, and is associated with a poor prognosis. In a previous study, MSI2 was demonstrated to be downregulated in grade II GC (15). Our group inferred that a larger sample size may lead to a clearer conclusion regarding the function of MSI2 in GC.

In the present study, our group investigated the associations between MSI2 expression levels and clinicopathological characteristics of patients with GC, and its biological functions. Differences in MSI2 expression were examined in 67 pairs of GC tissues and non-cancerous tissues. Reverse transcription-quantitative polymerase chain reaction (RT-qPCR) 
analysis revealed that MSI2 mRNA was overexpressed in the majority of GC tissues, although no significance was observed. The aforementioned results were confirmed by western blot analysis of 8 pairs of tissues. The associations with clinicopathological factors were then examined, and the results revealed that the expression level of MSI2 mRNA was positively associated with invasion depth, tumor-node-metastasis (TNM) stage (16), degree of differentiation and tumor size. The expression levels of MSI2 were then examined in the GC cell line MKN-28, and gain-of-function assays were performed. The results indicated that MSI2 promoted MKN-28 cell proliferation, migration, invasion and neovascularization in vitro.

\section{Materials and methods}

Cell lines. Human umbilical vein endothelial cells (HUVECs) and the gastric MKN-28 cell line was originally purchased from National Infrastructure of Cell Line Resource of China (Beijing, China). This cell line was determined to be derived from MKN-74 cells (http://cellbank.nibiohn. go.jp/ cellbank/en/search_res_det.cgi?ID=340), and the authors have checked for contamination as described previously (17). Cells were cultured in Hyclone ${ }^{\mathrm{TM}}$ RPMI-1640 medium (Hyclone; GE Healthcare Life Sciences, Logan, UT, USA) with $10 \%$ Hyclone fetal bovine serum (FBS; Hyclone; GE Healthcare Life Sciences) at $37^{\circ} \mathrm{C}$ with $5 \% \mathrm{CO}_{2}$.

Clinical samples and data collection. Of the available sample from patients with GC, a number had been used for previous study and the amount of tissue remaining was insufficient for the present study A total of 67 patients with GC with sufficient tissue for mRNA and protein extraction were selected for the present study treated at the Department of Gastrointestinal Surgery, Shandong Provincial Hospital Affiliated to Shandong University (Jinan, China) from January 2012 to December 2012. None patients had undergone treatments prior to surgery. GC tissue samples and adjacent non-cancerous tissue samples $5 \mathrm{~cm}$ from tumor margin were obtained from the aforementioned patients. And the tissues were stored at $-80^{\circ} \mathrm{C}$. The present study was approved by the Research Ethics Committee of Shandong Provincial Hospital Affiliated to Shandong University and all patients provided written informed consent.

$R T-q P C R$. Total RNA was extracted from GC tissue samples and adjacent non-cancerous tissue samples using RNAiso Plus reagent (cat. no. 9108/9109; Takara Bio, Inc., Otsu, Japan) according to the manufacturer's protocol. The RNA was reverse transcribed in a $20 \mu 1$ reaction volume using the PrimeScript $^{\mathrm{TM}}$ RT reagent kit (cat. no. RR047A; Takara Bio, Inc.) according to the manufacturer's protocol, with $2.0 \mu \mathrm{l} 5 \mathrm{X}$ gDNA Eraser Buffer, $1.0 \mu \mathrm{l}$ gDNA Eraser, $1.0 \mu \mathrm{g}$ total RNA and an equal amount of RNase Free $\mathrm{dH}_{2} \mathrm{O}$, incubated at room temperature for $5 \mathrm{~min}$, and $4.0 \mu \mathrm{l}$ 5X PrimeScript Buffer 2, 1.0 $\mu \mathrm{l}$ PrimeScript RT Enzyme Mix I, 1.0 $\mu \mathrm{l}$ RT Primer Mix*4, $4.0 \mu \mathrm{l}$ RNase Free $\mathrm{dH}_{2} \mathrm{O}$ and $10.0 \mu \mathrm{l}$ RNA template incubated at $37^{\circ} \mathrm{C}$ for $15 \mathrm{~min}$ followed by $85^{\circ} \mathrm{C}$ for $5 \mathrm{sec}$ and $4^{\circ} \mathrm{C}$ for 30 min. qPCR analyses were performed with SYBR Premix Ex $\mathrm{Taq}^{\mathrm{TM}}$ II (Takara Bio, Inc.) using GAPDH as a reference gene. The PCR conditions were as following: denatured at $95^{\circ} \mathrm{C}$ for $30 \mathrm{sec}$, followed by amplification at $95^{\circ} \mathrm{C}$ for $5 \mathrm{sec}$ and $60^{\circ} \mathrm{C}$ for $30 \mathrm{sec}$ for 40 cycles. RT-qPCR of MSI2 mRNA expression was performed using the LightCycler 480 Real-Time PCR system (Roche Diagnostics, Basel, Switzerland), with each sample triplicated. $\Delta \Delta \mathrm{Cq}$ was used to quantify the expression levels of MSI2 mRNA (18). The primer sequences used were as follows: MSI2 forward, 5'-GCAACGGCCTTTACAAAT GGATAC-3' and reverse, 5'-CAGGTCTGAGGACATCAC CTAAACA-3'; GAPDH forward, 5'-GCACCGTCAAGGCTG AGAAC-3' and reverse, 5'-TGGTGAAGACGCCAGTGGA-3'.

Western blotting. Total protein from GC and adjacent non-cancerous tissue samples was extracted with RIPA Lysis Buffer (Beyotime Institute of Biotechnology, Shanghai, China) for $30 \mathrm{~min}$ at $4^{\circ} \mathrm{C}$, with supernatant collected following $12,000 \times \mathrm{g}$ centrifugation. The extracted protein was quantified with a Bicinchoninic Acid Protein Assay kit (Beyotime Institute of Biotechnology). Protein samples $(\sim 40 \mu \mathrm{g})$ were added to each lane, separated using 10\% SDS-PAGE, and transferred to polyvinylidene fluoride (PVDF) membranes (GE Healthcare, Chicago, IL, USA). The PVDF membranes were blocked with $5 \%$ skimmed milk powder for $1 \mathrm{~h}$ at room temperature and washed three times with tris-buffered saline with Tween-20 (TBST), incubated with specific monoclonal primary antibodies against MSI2 (cat. no. ab76148; 1:1,000; Abcam, Cambridge, UK) at $4^{\circ} \mathrm{C}$ overnight, and then incubated with peroxidase-conjugated affinipure goat anti-rabbit immunoglobulin G antibodies (cat. no. ZB-2301; 1:5,000; OriGene Technologies, Inc., Beijing, China) for $1 \mathrm{~h}$ at room temperature and washed with TBST three times. Protein levels were normalized to total $\beta$-actin with mouse monoclonal antibody (cat. no. ab8226; 1:1,000; Abcam). The protein expression level was detected by ImageQuant LAS 4000 mini Biomolecular Imager (GE Healthcare Life Sciences) with Immobilon ${ }^{\mathrm{TM}}$ Western Chemiluminescent HRP Substrate (EMD Millipore, Billerica, MA, USA). Image J (Version 2; National Institutes of Health, Bethesda, MD, USA) was used for the quantification of grey level of bands.

Transfection of MSI2 into MKN-28 cells. The MSI2 overexpression vector pEGFP-N1-MSI2 was constructed by Shanghai Harmonious One Biotechnology Co., Ltd. (Shanghai, China). A total of $4 \times 10^{5}$ cells were seeded in 6 -well cell culture plates $\sim 24 \mathrm{~h}$ prior to transfection. For transfection, $10 \mu$ l Lipofectamine 2000 Reagent (Thermo Fisher Scientific, Inc.) and $4 \mu \mathrm{g}$ plasmid vectors were prepared and mixed with Opti-MEM medium (Thermo Fisher Scientific, Inc.) according to the manufacturer's protocol, and added to 6-well culture plates with a total of $2 \mathrm{ml}$ medium. Cells transfected with pEGFP-N1 (Shanghai Qihe Biotechnology Co., Ltd., Shanghai, China) were used as the control. Following $6 \mathrm{~h}$ transfection, the medium was replaced and the fluorescence activity of green fluorescent protein was used to measure transfection efficiency $24 \mathrm{~h}$ after transfection, and the nuclei were stained with DAPI. The images were captured using an inverted fluorescence microscope (Nikon Ti-S; Nikon Corporation, Tokyo, Japan). MSI2 protein expression levels were measured by western blotting, as aforementioned.

Cell proliferation assays. Colony formation assays were performed to evaluate cell proliferation. Cells transfected with 
the aforementioned vectors were trypsinized into single cell suspensions, and $1 \times 10^{3}$ cells were seeded in $35 \mathrm{~cm}^{2}$ culture plates with 2 ml RPMI-1640 medium with $10 \%$ FBS. The cells were stained with hematoxylin for $10 \mathrm{~min}$ at $37^{\circ} \mathrm{C}$ following culture at $37^{\circ} \mathrm{C}$ with $5 \% \mathrm{CO}_{2}$ for 2 weeks.

A Cell Counting Kit-8 (CCK-8) assay was also performed to assess GC cell proliferation. A total of $2.5 \times 10^{3} \mathrm{MKN}-28$ cells, transfected as aforementioned, were seeded in 96-well plates and cultured with $100 \mu \mathrm{l}$ RPMI-1640 medium with $10 \%$ FBS at $37^{\circ} \mathrm{C}$ with $5 \% \mathrm{CO}_{2}$. After 24,48 and $72 \mathrm{~h}$ culture, $10 \mu \mathrm{l}$ CCK-8 (Dojindo Molecular Technologies, Inc., Kumamoto, Japan) was added to each plate and cultured at $37^{\circ} \mathrm{C}$ with $5 \%$ $\mathrm{CO}_{2}$ for $1 \mathrm{~h}$. The optical density (OD) at $450 \mathrm{~nm}$ was measured to assess cell proliferation, and each group was replicated five times in total.

Invasion and migration assays. Transwell assays were performed to measure the invasion and migration MKN-28 cell, transfected as aforementioned. For the invasion assay, $50 \mu \mathrm{l}$ diluted Matrigel (BD Biosciences, San Jose, CA, USA) was added in the upper chamber of Transwell plates (24-well plate inserts, $8 \mu \mathrm{m}$ pore size; Corning Incorporated, Corning, NY, USA). Then, $6 \times 10^{5}$ cells were seeded in $200 \mu 1$ RPMI-1640 medium with $0.5 \%$ bovine serum albumin (Sigma-Aldrich; Merck KGaA, Darmstadt, Germany), and $500 \mu$ l RPMI-1640 medium with $10 \%$ FBS was added to each lower chamber. For the migration assays, no Matrigel was added to the upper chamber and $8 \times 10^{4}$ cells were seeded. All of the 24 -well culture plates used for the invasion and migration assays were incubated at $37^{\circ} \mathrm{C}$ with $5 \% \mathrm{CO}_{2}$ for $24 \mathrm{~h}$. Finally, after wiping off the non-migrated or non-invaded cells in the upper chamber with a cotton swab, the membranes were separated and stained with hematoxylin. The cells that had penetrated to the lower chamber were counted and photographed using a light microscope (Leica DM4000B; Leica Microsystems GmbH, Wetzlar Germany), and mean level of three fields was used for evaluation.

Wound healing assays were also performed to confirm the migratory function of transfected MKN-28 cells. GC cells were seeded into 6-well plates with $2 \mathrm{ml}$ RPMI-1640 medium with $10 \%$ FBS and permitted to grow to $90 \%$ confluence. Then, a wound field was made using a sterile $200 \mu 1$ pipette tip. Separated cells were detached with $2 \mathrm{ml}$ RPMI-1640 medium without FBS. The cells were then incubated at $37^{\circ} \mathrm{C}$ with $5 \% \mathrm{CO}_{2}$. Pictures were captured using a digital camera system at 2 time points ( 0 and $48 \mathrm{~h}$ ) and migration distance was used to evaluate migration activity.

Tube formation assay in HUVECs. GC cells, transfected as aforementioned, were plated in 6-well culture plates with $2 \mathrm{ml}$ RPMI-1640 medium with 10\% FBS. When cells reached $~ 90 \%$ confluence, they were washed twice with PBS buffer and the medium was changed to 2 ml RPMI-1640 medium with $10 \%$ FBS. After $24 \mathrm{~h}$ culture in an incubator at $37^{\circ} \mathrm{C}$ with $5 \% \mathrm{CO}_{2}$, the conditional media were collected. A total of $100 \mu 1$ growth-factor reduced Matrigel (BD Biosciences) was used to coat a 96-well plate, and HUVECs $\left(5 \times 10^{3}\right)$ were seeded and cultured at $37^{\circ} \mathrm{C}$ with $5 \% \mathrm{CO}_{2}$. HUVECs cultured in the conditional media were observed using a light microscope (Leica Microsystems $\mathrm{GmbH}$ ) after 6-8 h culture. Numbers of tubes were used to evaluate the tube formation ability. And tubes in three fields were counted.

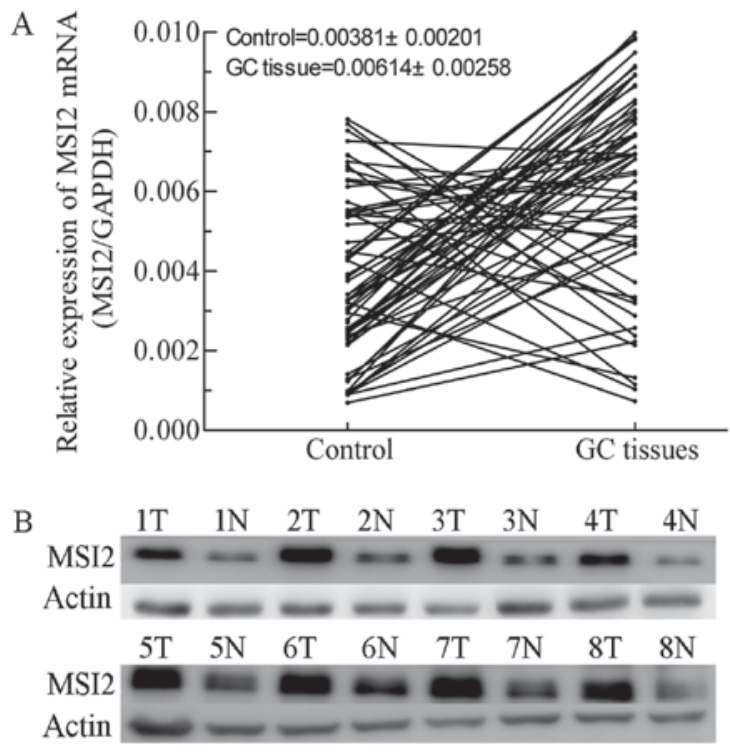

Figure 1. MSI2 expression in GC tissue samples. (A) MSI2 mRNA expression in 67 pairs of tissue samples, assessed using reverse transcription-quantitative polymerase chain reaction. MSI2 mRNA expression levels in the tissue samples were described using the relative expression of MSI2 mRNA compared with endogenous reference GAPDH mRNA expression. MSI2 mRNA expression was upregulated in the majority of GC tissue samples compared with the adjacent non-cancerous control tissues. However, no significance was observed. (B) MSI2 protein expression in 8 pairs of tissue samples, assessed using western blotting. MSI2, musashi 2; GC, gastric cancer; $\mathrm{N}$, normal adjacent tissue; $\mathrm{T}$, tumor tissue.

Statistical analysis. Statistical analysis was performed using SPSS 18.0 software (SPSS, Inc., Chicago, IL, USA). The OD values are expressed as the mean \pm standard deviation of at least three separate experiments, and the $\mathrm{OD}_{450}$ values are expressed as the mean \pm standard deviation of at least five separate experiments. The $\chi^{2}$ test was used to calculate the associations between clinicopathological characteristics, and the independent samples Student's t test was used to analyze the differences between MSI2 overexpression groups and vector groups. Overall survival was assessed using the Kaplan-Meier method with log rank test. $\mathrm{P}<0.05$ was considered to indicate a statistically significant difference.

\section{Results}

MSI2 is upregulated in GC tissues and is associated with clinicopathological features of patients with GC. Although a previous investigation of 30 pairs of GC tissues and paired normal tissues revealed that MSI 2 mRNA expression levels were not significantly different (15), analysis of a larger number of samples in the present study revealed that MSI 2 mRNA expression levels were increased in the majority of GC tissues compared with adjacent normal controls, although there was no significant difference (Fig. 1A). MSI2 protein expression was also upregulated in 8 pairs of tissues (Fig. 1B). Next, two folds of MSI2 mRNA expression, compared with adjacent non-cancerous tissues was set as the cut-off value, and the associations between MSI2 mRNAs levels and clinicopathological features of patients with GC were investigated in 67 pairs of tissues. The results revealed that MSI 2 mRNA overexpression was associated with invasion depth, TNM stage, degree of 
Table I. Associations between MSI2 mRNA expression and clinicopathological features of patients with gastric cancer.

\begin{tabular}{|c|c|c|c|}
\hline $\begin{array}{l}\text { Clinicopathological } \\
\text { feature }\end{array}$ & $\mathrm{n}$ & $\begin{array}{c}\text { MSI2 } \\
\text { overexpression } \\
\geq 2 \text {-fold, } \mathrm{n}(\%)\end{array}$ & P-value \\
\hline Sex & & & 0.565 \\
\hline Male & 51 & $31(60.8)$ & \\
\hline Female & 16 & $11(68.8)$ & \\
\hline Age, years & & & 0.094 \\
\hline$<60$ & 33 & $24(72.7)$ & \\
\hline$\geq 60$ & 34 & $18(52.9)$ & \\
\hline Location & & & 0.726 \\
\hline Proximal & 25 & $15(60.0)$ & \\
\hline Distant & 42 & $27(64.3)$ & \\
\hline Invasion depth & & & 0.017 \\
\hline $\mathrm{T} 1+\mathrm{T} 2$ & 16 & $6(37.5)$ & \\
\hline $\mathrm{T} 3+\mathrm{T} 4$ & 51 & $36(70.6)$ & \\
\hline Metastasis & & & 0.270 \\
\hline No & 14 & $7(50.0)$ & \\
\hline Yes & 53 & $35(66.0)$ & \\
\hline TNM stage & & & 0.028 \\
\hline Stage I and II & 19 & $8(42.1)$ & \\
\hline Stage III and IV & 48 & $34(70.8)$ & \\
\hline Differentiation & & & 0.020 \\
\hline Well-differentiated & 28 & $14(50.0)$ & \\
\hline Poorly differentiated & 39 & 26 (66.7) & \\
\hline Tumor size, $\mathrm{cm}^{2}$ & & & 0.029 \\
\hline Cutting area $\leq 6$ & 34 & $17(50.0)$ & \\
\hline Cutting area $>6$ & 33 & $25(75.8)$ & \\
\hline
\end{tabular}

MSI2, musashi 2; TNM, tumor-node-metastasis.

differentiation and tumor sizes $(\mathrm{P}<0.05$; Table I). However, no associations were observed between MSI2 mRNA expression levels and other clinicopathological characteristics including sex, age, tumor location and human epidermal growth factor receptor 2 expression.

Upregulation of MSI2 is associated with poor prognosis in GC. The overall survival of patients with GC following surgery was analyzed using the Kaplan-Meier method. The patients were classified into two groups according to the relative expression of MSI2 (MSI2 mRNA/GAPDH mRNA): A low expression group with 25 patients (group 1; cancer/normal <2) and a high expression group with 42 patients (group 2; cancer/normal $\geq 2$ ). The overall survival rate was significantly lower in group 1 (Fig. $2 ; \chi^{2}=4.221, \mathrm{P}=0.040$ ), indicating that MSI2 expression is associated with a poor prognosis in GC.

MSI2 promotes GC cell proliferation, migration and invasion. MKN-28 cells were transfected with pEGFP-N1 with a reporter gene encoding green fluorescence protein, and the transfection efficiency was verified by inverted fluorescence microscopy

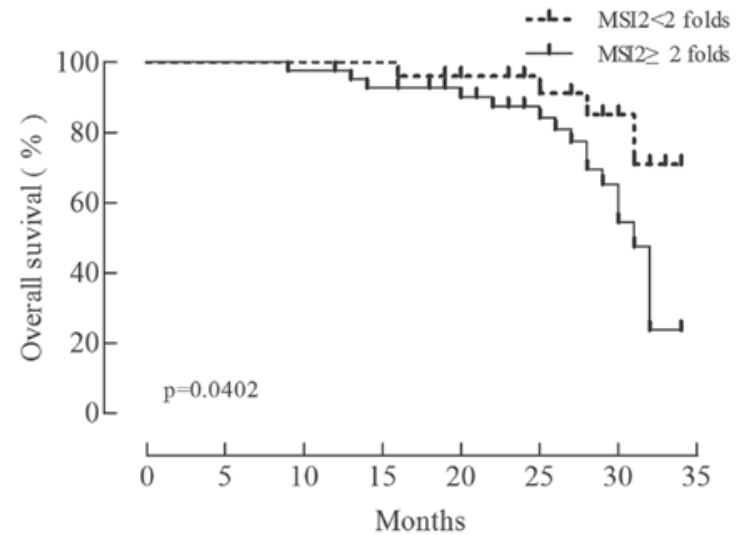

Figure 2. Overall survival in patients with gastric cancer. Patients with increased MSI 2 expression ( $\geq 2$ fold compared with adjacent non-cancerous tissues) had a poorer prognosis compared with those with $<2$ fold overexpression. MSI2, musashi 2.

and western blotting (Fig. 3). MSI2 expression was successfully induced in MKN-28 cells by pEGFP-N1-MSI2, and an empty vector was used as the negative control. The results of the colony formation assay revealed that colony numbers were significantly increased in the MSI2 group compared with the control group (Fig. 4A and B), and the results of the CCK-8 assay revealed that MKN-28 cells overexpressing MSI 2 proliferate faster than MKN-28 cells transfected with the empty vector (Fig. 4C). To assess the effects of MSI2 on GC cell migration and invasion, Transwell assays and wound healing assays were performed in MKN-28 cells following transfection with MSI2 expression vectors and the corresponding empty vector control. The results of the wound healing assay demonstrated that cells in the MSI2-overexpression group migrated further than those in the empty vector control group (Fig. 5A and B), and the Transwell assay results for invasion and migration revealed that the number of cells in the lower chambers were significantly increased in the MSI2-overexpression group compared with the control group (Fig. 5C and D). Taken together, these results indicated that MSI2 promotes GC cell proliferation, migration and invasion.

MSI2 promotes tube formation in vivo. To assess the effects of MSI2 on tube formation in HUVECs, a Matrigel tube formation test was performed. The results revealed that the tubular formation activity of MSI2-overexpression MKN-28 cells was significantly increased compared with the empty vector control (Fig. 6). These results indicated that MSI2 promotes tubular formation in HUVECs in vitro.

\section{Discussion}

GC remains a substantial threat to human health $(2,3)$. Although the overall survival of patients with GC has increased (19), outcomes in China remain worse than that in the USA at present (20). Although developments in endoscopic screening and biopsies have improved screening strategies for early stage GC, and laparoscopic resection has increased the ratio of early stage patients that receive treatment (21), endoscopic screening is impractical in general clinical practice due to its invasive nature. Furthermore, the biological mechanisms 

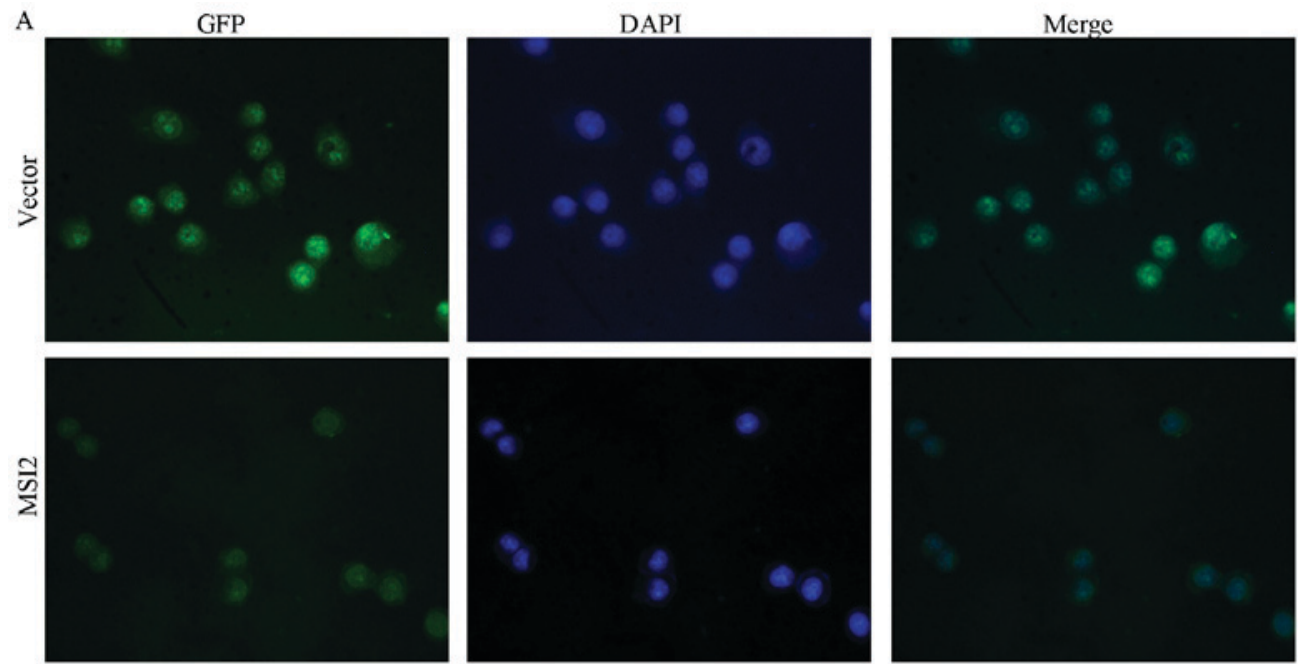

B

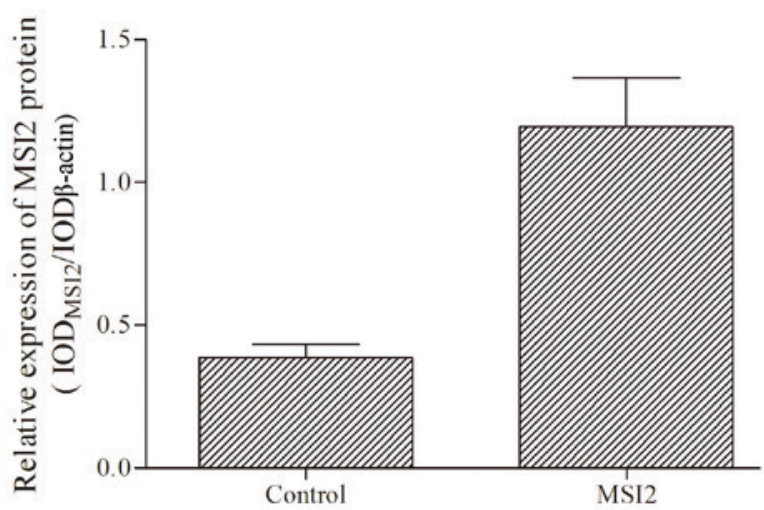

Figure 3. Verification of transfection efficiency in MKN-28 cells. MSI2 and vector were successfully transfected into MKN-28 cells. (A) Inverted fluorescence microscope screening results. Magnification, x900. Vector transfections were confirmed by GFP fluorescence, and the nuclei were stained with DAPI. (B) Western blotting verification of the results. MSI2 protein expression was described as the relative expression of MSI2 protein compared with the corresponding $\beta$-actin protein expression, and gray level of the band were used to describe the level of protein expression. MSI2 expression was significantly higher in the group transfected with MSI2-overexpression vectors compared with the group transfected with empty control vectors. MSI2, musashi 2; GFP, green fluorescent protein.

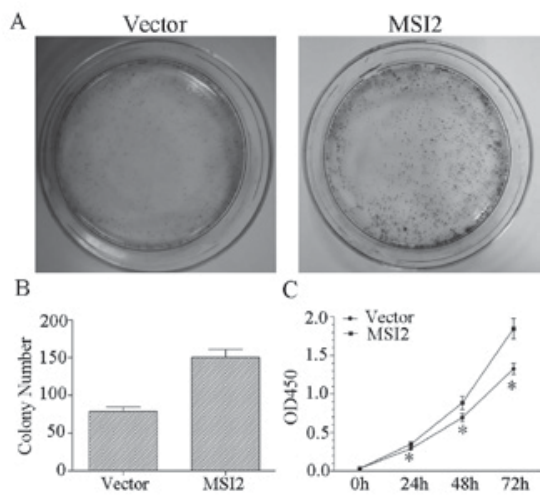

Figure 4. Overexpression of MSI2 promoted the proliferation of the gastric cancer cell line MKN-28. (A) Overexpression of MSI2 promoted colony formation in $\mathrm{MKN}-28$ cells, and (B) colony number was used to evaluate colony forming activity. (C) Overexpression of MSI2 promoted MKN-28 cell proliferation, as assessed using Cell-Counting Kit-8. MSI2, musashi 2. ${ }^{*} \mathrm{P}<0.05$ vs. empty vector transfected cells

underlying GC still remain to be comprehensively elucidated, although GC tumorigenesis and development are known to be long, multistep processes involving various genetic alterations, including oncogenic activation and the inactivation of tumor suppressor pathways (22). However, since the biological mechanisms GC remain unclear, prolonging the overall survival of patients with GC by improving treatment strategies will be difficult. Therefore, the discovery of novel biomarkers, regulatory molecules and therapeutic targets for GC will help to improve the prognosis of GC and overall public health.

MSI2 is a member of the MSI family, which is involved in the maintenance of stem cells and the regulation of cell differentiation $(9,10)$. MSI2 is involved in the development of the central nervous system, and binds to the poly A-binding protein to regulate gene expression at the post-transcriptional level (23). Previously, MSI2 was indicated to be involved in GC; however, no alteration of MSI2 expression levels were observed and decreased expression levels in grade II GC were observed (15). However, the use of MSI2 as a biomarker for $\mathrm{GC}$ and its involvement in the regulation of GC remain to be fully elucidated.

MSI2 has been demonstrated to be involved in malignancies of the circulatory system and to promote a malignant phenotype $(12,24,25)$, and has also been indicated to be dysregulated in several types of solid cancer, and to promote the malignant activity of these cancer cells. MSI2 has been demonstrated to be associated with tumor size, tumor differentiation, the number of tumor nodules, Barcelona clinic 
A

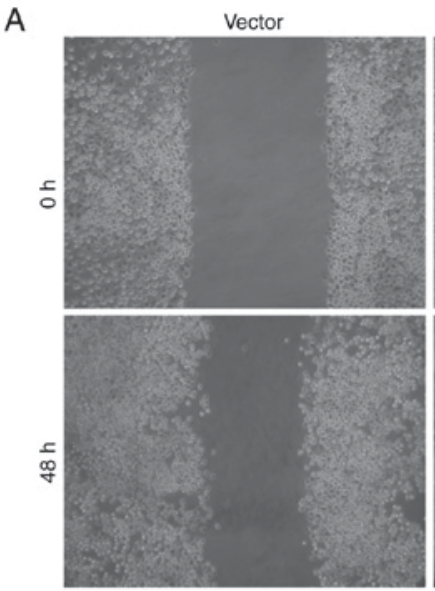

C

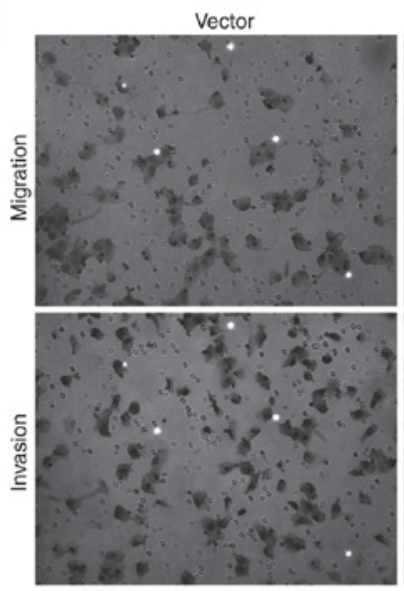

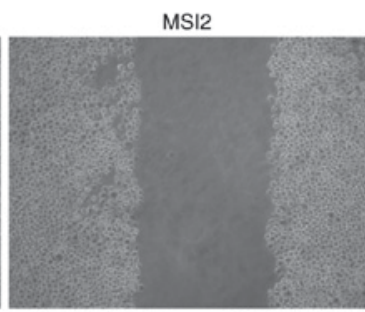
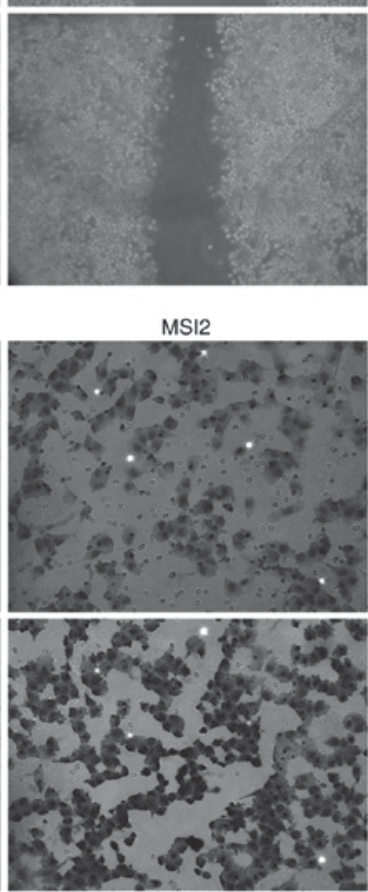

B
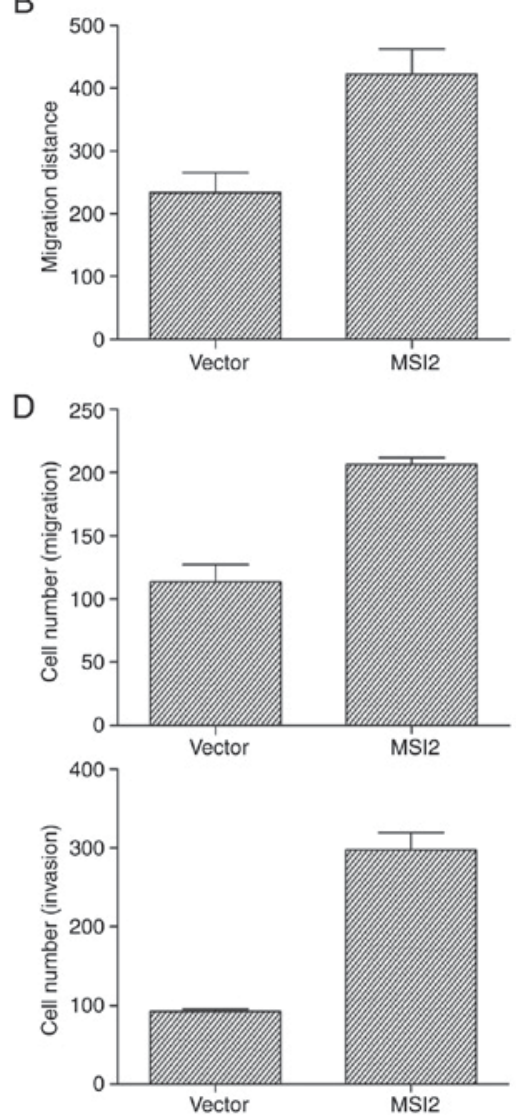

Figure 5. Overexpression of MSI2 promoted migration and invasion in MKN-28 cells. Magnification, x200. (A and B) MSI2 transfected MKN-28 cells had improved activation of migration assessed with wound healing assays, compared with vector transfected cells. (C and D) MSI2 transfected MKN-28 cells had improved activation of migration and invasion assessed with transwell assays, compared with vector transfected cells. MSI2, musashi 2.
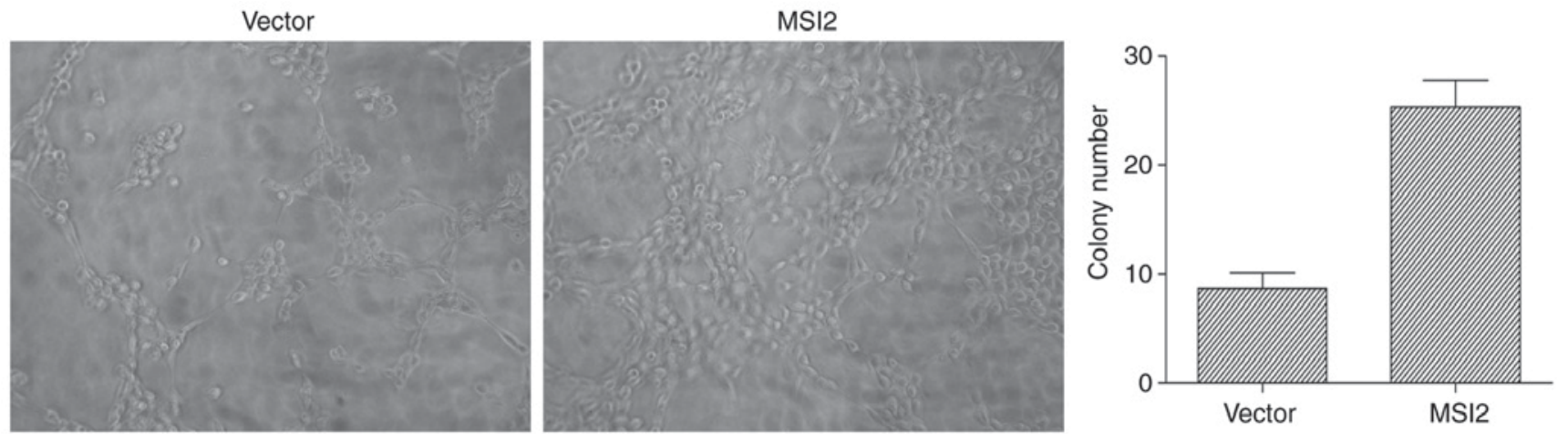

Figure 6. Overexpression of MSI2 promoted the tube formation ability of HUVECs. Magnification, x200. MSI2 transfected MKN-28 cells had a greater tube number, compared with vector transfected cells. Tube number was used to evaluate the activity. MSI2, musashi 2.

liver cancer stage, vascular invasion, recurrence and poor prognosis in HCC $(13,26)$. In the present study, the expression levels of MSI2 mRNA and protein in GC tissues and adjacent non-cancerous tissues were assessed using by RT-qPCR and western blotting, respectively. The results suggested that MSI2 was upregulated in the majority of GC tissues compared with adjacent non-cancerous tissues, although there was no significant difference. To classify the clinical value of MSI2, the associations between MSI2 and the clinicopathological features of patients with GC were than analyzed. The results revealed that MSI2 expression levels were associated with malignant GC phenotypes, including invasion depth, TNM stage, degree of differentiation and tumor size. Furthermore, overexpression of MSI2 resulted in a poorer prognosis in patients with GC. Taken together, the aforementioned results indicate that MSI2 is a potential valuable biomarker for the diagnosis of GC and for determining GC prognosis, as it has oncogenic functions.

The differences between cancercells and normal cells include sustained proliferation, the evasion of growth suppression, 
resistance to cell death, replicative immortality, angiogenesis, invasion and metastasis (27). MSI2 has been demonstrated to promote $\mathrm{HCC}$ invasion and progression by activating EMT or via the Wnt/ $\beta$-catenin signaling pathway $(13,26)$. To investigate the biological functions of MSI2 in GC cells, MSI2 expression was induced by transfection of an expression vector into the GC cell line MKN-28, and gain-of-function assays were performed in vitro. CCK-8 and colony formation assays were performed to elucidate the function of MSI2 in GC cell proliferation. The results revealed that MSI2 overexpression resulted in increased proliferation in the MKN-28 cell line and an increased number of colonies, indicating that MSI2 promoted MKN-28 cell proliferation. Wound healing assays and Transwell migration and invasion assays were performed to investigate the involvement of MSI2 in GC cell migration and invasion. An increased number of cells recorded in the lower chambers and a decreased width of the scratch compared with the control group indicated that MSI2 promoted GC cell migration and invasion. The aforementioned results indicated MSI2 may serve oncogenic functions in GC by directly invading the extracellular matrix, which is the natural protective barrier, and migrating to adjacent organs. To explore whether MSI2 promoted GC metastasis in other ways, tubular formation assays were performed in HUVECs. The results revealed that more tubes were formed in the MSI2 overexpression group compared with the control group. This indicated that MSI2 promoted vessel formation activity in HUVECs, suggesting that MSI2 promotes angiogenesis. Taken together, these results indicate that MSI2 acts as an oncogene and is involved in the promotion of GC carcinogenesis and progression.

In conclusion, MSI2 mRNA and protein expression levels were increased in GC tissues, so it may be a potential biomarker for GC diagnosis following verification from a larger sample. Furthermore, MSI2 expression is associated with various malignant phenotypes, including invasion depth, TNM stage, degree of differentiation and tumor size, and is a risk factor for determining the prognosis of GC. The in vitro assays demonstrated that MSI2 promotes GC cell proliferation, migration, invasion and angiogenesis. These results indicated that MSI2 may act as an oncogene in GC by increasing proliferation and promoting metastasis via inducing migration, invasion and angiogenesis. However, the underlying mechanisms and signaling pathways remain unclear, and further investigations with a large scale of samples and GC cell lines are required to assess the potential clinical applications of MSI2.

\section{Acknowledgements}

Not applicable.

\section{Funding}

The present study was supported by grants from the National Natural Science Foundation of China (grant nos. 81672379 and 81572355), the Natural Science Foundation of Shandong Province (grant nos. ZR2015HM078 and ZR2016HM16) and the Taishan Young Scholars Foundation of Shandong Province (grant no. TSQN20161072). The processes of study design, data collection, analysis and interpretation and manuscript writing had no funding body participation.

\section{Availability of data and materials}

The datasets used and/or analyzed during the current study are available from the corresponding author on reasonable request.

\section{Authors' contributions}

XG designed the experiment, provided financial support, revised the manuscript and gave final approval of the version to be published. XG was responsible for the interpretation of data. ZY and JL performed the experiments, acquired the data and wrote the paper. YS and LL made substantive contibutions to the work, including data collecting and manuscript revising..

\section{Ethics approval and consent to participate}

The present study was approved by the Research Ethics Committee of Shandong Provincial Hospital Affiliated to Shandong University (approval no. 2012-101) and all patients provided written informed consent to participate.

\section{Patient consent for publication}

The patients' data was anonimised, and hospital numbers and associated data may be provided only for scientific purposes. All patients provided written informed consent that their data may be published.

\section{Competing interests}

The authors declare that they have no competing interests.

\section{References}

1. Ferlay J, Soerjomataram I, Dikshit R, Eser S, Mathers C, Rebelo M, Parkin DM, Forman D and Bray F: Cancer incidence and mortality worldwide: Sources, methods and major patterns in GLOBOCAN 2012. Int J Cancer 136: E359-E386, 2015.

2. Bertuccio P, Chatenoud L, Levi F, Praud D, Ferlay J, Negri E, Malvezzi M and La Vecchia C: Recent patterns in gastric cancer: A global overview. Int J Cancer 125: 666-673, 2009.

3. Torre LA, Bray F, Siegel RL, Ferlay J, Lortet-Tieulent J and Jemal A: Global cancer statistics, 2012. CA Cancer J Clin 65: 87-108, 2015.

4. Lordick F and Terashima M: Gastric cancer adjuvant therapy. Best Pract Res Clin Gastroenterol 30: 581-591, 2016.

5. Catalano V, Labianca R, Beretta GD, Gatta G, de Braud F and Van Cutsem E: Gastric cancer. Crit Rev Oncol Hematol 54: 209-241, 2009.

6. Sugimura T, Terada M, Yokota J, Hirohashi S and Wakabayashi K: Multiple genetic alterations in human carcinogenesis. Environ Health Perspect 98: 5-12, 1992.

7. Guo X, Liu W, Pan Y, Ni P, Ji J, Guo L, Zhang J, Wu J, Jiang J, Chen X, et al: Homeobox gene IRX1 is a tumor suppressor gene in gastric carcinoma. Oncogene 29: 3908-3920, 2010.

8. Wang Z, Tang F, Qi G, Yuan S, Zhang G, Tang B and He S: $\mathrm{KDM} 5 \mathrm{~B}$ is overexpressed in gastric cancer and is required for gastric cancer cell proliferation and metastasis. Am J Cancer Res 5: 87-100, 2014.

9. Okano H, Imai T and Okabe M: Musashi: A translational regulator of cell fate. J Cell Sci 115: 1355-1359, 2002.

10. Siddall NA, McLaughlin EA, Marriner NL and Hime GR: The RNA-binding protein Musashi is required intrinsically to maintain stem cell identity. Proc Natl Acad Sci USA 103: 8402-8407, 2006.

11. Katz Y, Li F, Lambert NJ, Sokol ES, Tam WL, Cheng AW, Airoldi EM, Lengner CJ, Gupta PB, Yu Z, et al: Musashi proteins are post-transcriptional regulators of the epithelial-luminal cell state. Elife 3: e03915, 2014. 
12. Kharas MG, Lengner CJ, Al-Shahrour F, Bullinger L, Ball B, Zaidi S, Morgan K, Tam W, Paktinat M, Okabe R, et al: Musashi-2 regulates normal hematopoiesis and promotes aggressive myeloid leukemia. Nat Med 16: 903-908, 2010.

13. He L, Zhou X, Qu C, Hu L, Tang Y, Zhang Q, Liang M and Hong J: Musashi2 predicts poor prognosis and invasion in hepatocellular carcinoma by driving epithelial-mesenchymal transition. J Cell Mol Med 18: 49-58, 2014.

14. Wang S, Li N, Yousefi M, Nakauka-Ddamba A, Li F, Parada K, Rao S, Minuesa G, Katz Y, Gregory BD, et al: Transformation of the intestinal epithelium by the MSI2 RNA-binding protein. Nat Commun 6: 6517, 2015.

15. Emadi-Baygi M, Nikpour P, Mohammad-Hashem F, Maracy MR and Haghjooy-Javanmard S: MSI2 expression is decreased in grade II of gastric carcinoma. Pathol Res Pract 209: 689-691, 2013.

16. Sobin LH, Gospodarowicz MK and Wittekind C: TNM classification of Malignant Tumours. 7th edition. Wiley-Blackwell, Hoboken, NJ, 2009.

17. Capes-Davis A, Theodosopoulos G, Atkin I, Drexler HG Kohara A, MacLeod RA, Masters JR, Nakamura Y, Reid YA, Reddel RR and Freshney RI: Check your cultures! A list of cross-contaminated or misidentified cell lines. Int J Cancer 127: $1-8,2010$.

18. Livak KJ and Schmittgen TD: Analysis of relative gene expression data using real-time quantitative PCR and the 2(-Delta Delta $\mathrm{C}(\mathrm{T})$ ) method. Methods 25: 402-8, 2001.

19. Zheng L, Wu C, Xi P, Zhu M, Zhang L, Chen S, Li X, Gu J and Zheng Y: The survival and the long-term trends of patients with gastric cancer in Shanghai, China. BMC Cancer 14: 300, 2014.

20. Strong VE, Wu AW, Selby LV, Gonen M, Hsu M, Song KY, Park CH, Coit DG, Ji JF and Brennan MF: Differences in gastric cancer survival between the U.S. and China. J Surg Oncol 112: 31-37, 2015.
21. Leja M, You W, Camargo MC and Saito H: Implementation of gastric cancer screening-the global experience. Best Pract Res Clin Gastroenterol 28: 1093-1106, 2014.

22. Figueiredo C, Costa S, Karameris A and Machado JC: Pathogenesis of gastric cancer. Helicobacter 20 (Suppl 1): S30-S35, 2015.

23. Sakakibara S, Nakamura Y, Satoh $\mathrm{H}$ and Okano H: Rna-binding protein Musashi2: Developmentally regulated expression in neural precursor cells and subpopulations of neurons in mammalian CNS. J Neurosci 21: 8091-1107, 2001.

24. Mansouri L, Gunnarsson R, Sutton LA, Ameur A, Hooper SD, Mayrhofer M, Juliusson G, Isaksson A, Gyllensten U and Rosenquist R: Next generation RNA-sequencing in prognostic subsets of chronic lymphocytic leukemia. Am J Hematol 87: 737-740, 2012.

25. Thol F, Winschel C, Sonntag AK, Damm F, Wagner K, Chaturvedi A, Göhring G, Schlegelberger B, Lubbert M, Fiedler W, et al: Prognostic significance of expression levels of stem cell regulators MSI2 and NUMB in acute myeloid leukemia. Ann Hematol 92: 315-323, 2013.

26. Wang MH, Qin SY, Zhang SG, Li GX, Yu ZH, Wang K, Wang B, Teng MJ and Peng ZH: Musashi-2 promotes hepatitis Bvirus related hepatocellular carcinoma progression via the Wnt/ß-catenin pathway. Am J Cancer Res 5: 1089-1100, 2015.

27. Hanahan D and Weinberg RA: Hallmarks of cancer: The next generation. Cell 144: 646-674, 2011.

This work is licensed under a Creative Commons Attribution-NonCommercial-NoDerivatives 4.0 International (CC BY-NC-ND 4.0) License. 